\title{
Is Surrogate LH Surge Essential in All Induced Cycles?
}

\author{
MOSAMMAT RASHIDA BEGUM ${ }^{1}$, MARIYA EHSAN ${ }^{2}$, MOSAMMAT SHAHINA BEGUM ${ }^{3}$, FARZANA KHAN ${ }^{4}$, \\ MARUF SIDDIQI ${ }^{5}$, HOSNE ARABABY ${ }^{6}$
}

\begin{abstract}
:
Objective: Aim of this study was to identify the necessity of use of exogenous or surrogate $\mathrm{LH}$ for triggering of ovulation in induced cycles.

Materials and methods: This study was conducted in Infertility Care and Research Center (ICRC) Dhaka, Bangladesh. Three hundred anovulatory patients with polycystic ovarian syndrome (PCOS) were the target population for this study. The patients were treated by different ovulation inducing agents to produce mature follicles. When follicle got the size of 18 $\mathrm{mm}$ or more $\mathrm{LH}$ was given to 150 patients (Group A) and 150 patients did not receive $L H$ (Group B). Follicular rupture was monitored by USG. Main outcome measure was rupture of the follicle.

Result: In group A 33.33\% and in group B $34.67 \%$ patients responded by letrozole only, whereas $66.66 \%$ in group $A$ and $65.34 \%$ in group $B$ needed additional drugs like metformin glucocorticoids and gonadotropins. In both the groups response was similar in terms of number of follicular recruitment, follicular maturity, endometrial development and hormone production. Follicular rupture rate was similar in both $h C G$ and non-hCG treated group. LUFS was detected only in $2.67 \%$ in group $A$ and $2 \%$ cases in group $B$.
\end{abstract}

Conclusion: If follicular development is adequate exogenous $\mathrm{LH}$ is not necessary for triggering of ovulation in all stimulated cycles.

Key Wards: Induced cycle, Follicle, Rupture, LH

\section{Introduction:}

Ovulation induction is needed to make the women ovulatory in type 1 and type 11 anovulation and for superovulation in IUI and ART cycles. Induction causes ovulation by i) increasing the secretion of gonadotropins from pituitary ( $\mathrm{CC}$ and $\mathrm{Al}$ ), ii) by directly stimulating the ovaries (HMG, rFSH). In both the cases FSH causes follicular growth and development, which releases oestrogen from granulosa cells. Both oestrogen and $\mathrm{FSH}$ increases the number of $\mathrm{LH}$ receptors in granulosa cells. Simultaneously oestrogen sends signals to pituitary to increase responsiveness to $\mathrm{GnRH}$ to release bouts of $\mathrm{LH}$. This $\mathrm{LH}$ causes final maturation of follicles, resumption of meiosis, rupture of the follicles, extrusion of M11 ovum and luteinization of granulosa cells and production of progesterone. So to ovulation take place mid-cycle LH surge is mandatory. Appropriate timing, adequate duration and amplitude of the mid-cycle LH surge are the prerequisite for female fertility. Mid-cycle LH surge is governed by $\mathrm{GnRH}$, oestrogen, progesterone and peptide hormones like gonadotropin surge attenuating factor ${ }^{1}$.

In natural cycle sudden endogenous LH surge occurs due to oestrogen peak, which is called +ve feedback. For which hypothalamic pituitary function should be normal. Normal midcycle LH surge is $48.7 \pm 9.3$ hours $^{2}$. Follicles rupture 36 hours after onset of LH surge. During LH surge the level of $\mathrm{LH}$ becomes 10-20 times more than the basal level. The mean peak value is $46 \pm 16 \mathrm{IU} / \mathrm{L}$. The LH pulse frequency is same but

1. Professor and Head of the Department, AKMMC, Chief Consultant, Infertility Care and Research Centre (ICRC)

2. Medical Officer, Infertility Care and Research Centre (ICRC)

3. Consultant Gynaecologist and Embryologist, Infertility Care and Research Centre (ICRC)

4. Embryologist, Infertility Care and Research Centre (ICRC)

5. Assistant Professor, AKMMC, Consultant, Infertility Care and Research Centre (ICRC)

6. Professor, AKMMC, Consultant, Infertility Care and Research Centre (ICRC) 
amplitude becomes high ${ }^{3}$. But there are variations in duration and amplitude in different individuals. The threshold amplitude for LH surge for oocyte maturation is not known but only $5 \%$ of total LH peak is enough for resumption of meioses, $5 \%$ is sufficient for significant lutenization and rest is needed for rupture of the follicle and release of the ovum 4 .

\section{Exogenous LH surge is indicated in certain situations.}

1. In type 1 anovulation where pituitary is nonfunctioning

2. In down regulated cycles where pituitary LH synthesis is prevented by Gorham or LH receptor is blocked by $\mathrm{GnRH}$ antagonist.

\section{In IUI cycles for scheduling the time of IUI}

Surrogate $\mathrm{LH}$ is used for final maturation of the follicles and resumption of meiosis to develop a mature metaphase II oocyte, which is the rule for downregulated ART cycles. But in natural stimulated cycles without down-regulation LH function is not interfered. In those cases +ve feedback for LH surge should occur normally following optimum folliculogenesis. Mature follicle releases enough oestrogens from granulosa cells to induce LH surge, which happens in natural cycles. So in induced cycles once there is good follicular development then next sequence of events should be like natural cycles. On the other hand premature application of exogenous LH in unmonitored cycles causes atresia of follicles or anovulation due to premature lutenization. For that reason induced cycles should be monitored. But from couples point of view it is cumbersome to come for monitoring in each month. Moreover, it puts the patient on stress for unknown outcome of induction, which has got negative impact on reproduction. So it is better to avoid the use of exogenous or surrogate LH for induction of ovulation and natural trial. But it is necessary to confirm the ovulation without surrogate LH surge. So purpose of this study is to evaluate whether ovulation occurs or not without surrogate LH surge in induced cycles.

\section{Materials and methods:}

This study was conducted in Infertility Care and Research Center (ICRC) Dhaka, Bangladesh. Three hundred anovulatory patients with polycystic ovarian syndrome (PCOS) were the target population for this study. PCOS were diagnosed by revised Rotterdam criteria which included two of the following three findings i) oligo or anovulation ii) clinical and or biochemical signs of hyperandrogenism and iii) polycystic ovaries by ultrasonography [5]. Associated hypothyroidism and hyperprolactinemia were excluded from this study. Induction of ovulation was given by

1. Letrozole (Aromatase inhibitor) $5 \mathrm{mg}$ daily from D3 - D7 with increment of dose $2.5 \mathrm{mg}$ per cycle up to $10 \mathrm{mg}$ daily.

2. Letrozole $10 \mathrm{mg}$ daily from D3-D7 + Corticosteroids $.5 \mathrm{mg}$ on alternate day from D2D10 of cycle.

3. If failed to ovulate with above drugs then metformin was added $1500 \mathrm{mg}-2500 \mathrm{mg}$ daily according to BMI of the patients and continued. Dose of metformin was $1500 \mathrm{mg}$ for BMI up-to 29, 2000mg for BMI 30-34 and 2500mg for BMI 35 and above.

4. After 8 weeks of getting metformin, induction was given by Letrozole $10 \mathrm{mg}$ daily from D3-D7 + Corticosteroids $.5 \mathrm{mg}$ on alternate day from $\mathrm{D} 2-$ D10 of cycle+ Inj Gonadotropin (rFSH Gonal-F, Serono) 75 IU on D3 and D8 or D3, D5, D7 or D3, D5, D7 and D9 according to patient's response.

Monitoring was done on D12, D14 and D16 according to patient's response. Optimum response was defined by attainment of follicular size e"18mm and trilaminar endometrial development $8 \mathrm{~mm}$ or more. Patients were divided into two groups by lottery. One group (A) received exogenous injection LH or hCG 5000 IU intramuscularly (Inj Pregnyl, Organon) when follicle attained the size of $18 \mathrm{~mm}$ or more and other group (B) did not receive hCG. Both groups were further monitored to observe rupture of the follicle after 36,48 , and $72 \mathrm{hrs}$ of $\mathrm{hCG}$ administration in group $A$ and at same interval after follicular maturity in group B. Ovulation was confirmed by observing i) collapsing of follicle or ii) reduction of size of follicle $5 \mathrm{~mm}$ from previous measurement and iii) presence of fluid in POD. If follicle did not rupture within 72 hours of monitoring it was declared as LUFS. Main outcome measure of this study was rupture of follicles. Student $t$ test and chi square test were done and a p value of $<.05$ was considered as significance.

\section{Results:}

Demographic characteristics of both groups were similar regarding age, BMI, duration of marriage and type of infertility (Table 1). Baseline hormonal parameters like ESH, LH, E2 TSH and prolactin level were also similar in both groups (Table 2). Table 3 shows the drugs used for induction of ovulation. In group A 33.33\% and in group B $34.67 \%$ patients 
responded by letrozole only, whereas $66.66 \%$ in group $A$ and $65.34 \%$ in group $B$ needed additional drugs like metformin glucocorticoids and gonadotropins. One third patients responded with letrozole and glucocorticoids combination. Table 4 shows the response of the induction. In both the groups response was similar in terms of number of follicular recruitment, follicular maturity, endometrial development and hormone production. Follicular rupture or in other way rate of ovulation was also similar in both hCG and non-hCG group. LUFS was detected only in $2.67 \%$ in group $A$ and $2 \%$ cases in group $B$.

Table-I

Comparison of patient's characteristics

\begin{tabular}{|c|c|c|c|c|c|}
\hline Characteristics & \multicolumn{2}{|c|}{$\begin{array}{c}\text { Group A } \\
\text { Mean } \pm \text { SD }\end{array}$} & \multicolumn{2}{|c|}{$\begin{array}{c}\text { Group B } \\
\text { Mean } \pm \text { SD }\end{array}$} & Sig \\
\hline Age Yrs & \multicolumn{2}{|c|}{$25.96 \pm 4.05$} & \multicolumn{2}{|c|}{$25.84 \pm 5.13$} & .730 \\
\hline Body mass index $\left(\mathrm{kg} / \mathrm{m}^{2}\right)$ & \multicolumn{2}{|c|}{$27.71 \pm 3.61$} & \multicolumn{2}{|c|}{$28.36 \pm 4.54$} & .554 \\
\hline Duration of marriage (Yrs) & \multicolumn{2}{|c|}{$7.23 \pm 2.52$} & \multicolumn{2}{|c|}{$6.27 \pm 3.00$} & .524 \\
\hline \multirow[t]{2}{*}{ Duration of infertility (Yrs) } & \multicolumn{2}{|c|}{$6.13 \pm 2.38$} & \multicolumn{2}{|c|}{$5.06 \pm 3.04$} & .603 \\
\hline & No & $\%$ & No & $\%$ & \\
\hline \multirow[t]{2}{*}{ Type of infertilityPrimarySecondary } & 140 & 93.33 & 121 & 80.67 & \\
\hline & 10 & 6.67 & 29 & 19.33 & \\
\hline
\end{tabular}

Table -II

Comparison of baseline hormonal parameters

\begin{tabular}{lccc}
\hline Parameters & $\begin{array}{c}\text { Group A } \\
\text { Mean } \pm \text { SD }\end{array}$ & $\begin{array}{c}\text { Group B } \\
\text { Mean } \pm \text { SD }\end{array}$ & Sig \\
\hline FSH $(\mathrm{mlU} / \mathrm{mL})$ & $6.95 \pm 1.33$ & $6.79 \pm 1.50$ & .379 \\
$\mathrm{LH}(\mathrm{mlU} / \mathrm{mL})$ & $11.00 \pm 3.47$ & $11.61 \pm 3.45$ & .466 \\
E2 $(\mathrm{pg} / \mathrm{mL})$ & $68.87 \pm 17.64$ & $69.29 \pm 15.25$ & .344 \\
Prolactin $(\mathrm{ng} / \mathrm{mL})$ & $22.48 \pm 4.16$ & $22.22 \pm 5.67$ & .484 \\
TSH $(\mathrm{m} \mathrm{IU} / \mathrm{mL})$ & $3.99 \pm 1.21$ & $3.98 \pm 1.25$ & .451 \\
\hline
\end{tabular}

Table-III

Drugs used for ovulation induction

\begin{tabular}{|c|c|c|c|c|}
\hline \multirow[t]{2}{*}{ Ovulation inducing Drugs } & \multicolumn{2}{|c|}{ Group A } & \multicolumn{2}{|c|}{ Group B } \\
\hline & $\mathrm{N}$ & $\%$ & $\mathrm{~N}$ & $\%$ \\
\hline Letrozole 25 mg/cycle & 10 & 06.67 & 12 & 08.00 \\
\hline Letrozole $37.5 \mathrm{mg} / \mathrm{cycle}$ & 20 & 13.33 & 18 & 12.00 \\
\hline Letrozole 50 mg/cycle & 20 & 13.33 & 22 & 14.67 \\
\hline Letrozole 50 mg+ Corticosteroid $2.5 \mathrm{mg} /$ cycle & 50 & 33.33 & 52 & 34.67 \\
\hline Letrozole 50 mg+ Coricosteroid 2.5mg + FSH 150 IU/cycle + Metformin & 32 & 21.33 & 28 & 18.67 \\
\hline Letrozole 50 mg+ Coricosteroid 2.5mg + FSH 225 IU/cycle + Metformin & 10 & 06.67 & 10 & 06.67 \\
\hline Letrozole 50 mg + Coricosteroid 2.5mg + FSH $300 \mathrm{IU} /$ cycle + Metformin & 08 & 05.33 & 08 & 05.33 \\
\hline
\end{tabular}


Table-IV

Response to stimulation in terms of follicular maturity, endometrial development and rupture of the follicle

\begin{tabular}{|c|c|c|c|c|c|}
\hline & \multicolumn{2}{|c|}{$\begin{array}{c}\text { Group A } \\
\text { Mean } \pm S D\end{array}$} & \multicolumn{2}{|c|}{$\begin{array}{c}\text { Group B } \\
\text { Mean } \pm \text { SD }\end{array}$} & Sig \\
\hline Number of follicles (n) & \multicolumn{2}{|c|}{$2.64 \pm 1.00$} & \multicolumn{2}{|c|}{$2.71 \pm 1.05$} & 0.324 \\
\hline Size of the follicles (mm) & \multicolumn{2}{|c|}{$19.61 \pm 3.80$} & \multicolumn{2}{|c|}{$19.82 \pm 2.17$} & 0.591 \\
\hline Day needed for follicular maturity (days) & \multicolumn{2}{|c|}{$12.73 \pm 1.58$} & \multicolumn{2}{|c|}{$12.08 \pm 1.67$} & 0.277 \\
\hline Serum E2 level (pg/mL) & \multicolumn{2}{|c|}{$391.33 \pm 146.18$} & \multicolumn{2}{|c|}{$371 \pm 187.76$} & 0.497 \\
\hline Endometrial thickness (mm) & \multicolumn{2}{|c|}{$10.27 \pm 1.90$} & \multicolumn{2}{|c|}{$10.62 \pm 1.60$} & 0.74 \\
\hline \multirow{2}{*}{ Serum P4 level (ng/mL) } & \multicolumn{2}{|c|}{$27.21 \pm 5.42$} & \multicolumn{2}{|c|}{$28.49 \pm 6.85$} & 0.375 \\
\hline & $\mathrm{N}$ & $\%$ & $\mathrm{~N}$ & $\%$ & 0.000 \\
\hline Rupture of the follicle & 145 & 96.67 & 146 & 96.00 & 0.387 \\
\hline LUFS & 05 & 03.33 & 04 & 04.00 & 0.432 \\
\hline
\end{tabular}

\section{Discussion:}

The midcycle LH surge in the reproductive cycle is an intriguing endocrinological phenomenon. The exact details of the mechanism in many species including human are still unknown ${ }^{6}$. However, it is known that central signaling by hypothalamic $\mathrm{GnRH}$ is permissive. LH surge is an absolute requirement for final maturation of follicles, rupture of the follicles and lutenization. It is obvious that the organ containing the mature follicles ready to ovulate should send the crucial signals to pituitary. The timing of occurring of LH surge is governed by signals from ovaries ${ }^{6}$. The progressive rise of oestradiol from dominant follicle is the main signal, which causes pituitary sensitivity to $\mathrm{GnRH}$. It is postulated that several mechanisms are involved in the phenomenon like

- Oestrogen enhances pituitary sensitivity to $\mathrm{GnRH}$

- Non steroidal compound like activin increases in concentration and gonadotropin surge inhibiting factors decreases ${ }^{7}$.

- Subtle rise in progesterone concentration may augment LH secretory sensitivity to $\mathrm{GnRH}$ [8].

In natural cycle once the follicles begin to grow the dominant follicle produces rapidly increasing quantity of E2, which accomplish a variety of objectives. E2 enhances the number of granulosa cells and density of $\mathrm{FSH}$ receptors for further rapid proliferation of granulosa cells, and both FSH and oestrogen increase the number of $\mathrm{LH}$ receptors in granulosa cells. Oestrogen also increases the pituitary sensitivity to hypothalamic GnRH. Eighty percent oestrogen releases from dominant follicle so as to increase the both $\mathrm{FSH}$ and $\mathrm{LH}$ receptor in dominant follicle. Due to positive feedback of oestrogen LH surge occurs causing extrusion of ovum from dominant follicle. So there is no need of application of exogenous LH for extrusion of ovum or letienization of follicles in natural cycles. Then why there will be need of exogenous LH in stimulated cycles where follicular development is adequate?

In Bangladesh most of the fertility specialists have been using hCG routinely for triggering of ovulation in stimulatory cycles of natural trial (personal communication). In addition, many of the gynaecologists are using hCG on a fixed day in unmonitored cycle, which causes premature luteinization and atresia of follicles causing anovulation due to untimely use of the drug (review of prescriptions). Question arises whether it is essential to use surrogate LH routinely at all induced cycles? Seibel MM et al mentioned that FSH induced follicular growth does not usually lead to a correct timing and adequate amplitude of LH surge ${ }^{9}$. So surrogate LH is needed for FSH stimulated cycles. But Glasier A et al described that superovulation with exogenous gonadotropins does not inhibit the LH surge. But if multiple follicles develop then feedback mechanism may be disturbed and surrogate LH may be needed ${ }^{10}$. We compared 300 stimulated cycles with surrogate LH in 150 cycles and no LH in 150 cycles. In all the cases follicular development and oestrogen production was satisfactory. Average number of follicles was 2.64 and 2.71 in group A and B respectively. Follicular rupture rate was similar in both groups, $97 \%$ 
and $96 \%$ in group $A$ and $B$ respectively. Only $3 \%$ and $4 \%$ cases follicles remained unruptured in group $A$ and $B$ respectively. These number of unruptured follicles are not significant. LUF is seen in $10 \%$ of menstrual cycles of normal fertile women ${ }^{11}$. A higher incidence has been reported in infertile women ${ }^{12}$. The occurrence of LUF has been linked to many conditions such as unexplained infertility $50 \%{ }^{13}$, endometriosis $35 \%{ }^{14}$, pelvic adhesions, PID and the use of non-steroidal antiinflammatory drugs (NSAIDs) ${ }^{12,15,16}$. LUF has been demonstrated in both spontaneous and stimulated cycles $^{17}$ and even after administration of hCG in HMG stimulated cycles ${ }^{18}$. Sometimes it may occur due to defect in follicular wall. But this happening is not constant. It varies from cycle to cycle. In our series LUFS is non-significant in comparison to rate shown by others and rate is same in both hCG triggered and non hCG cycles. So from above findings it can be said that if stimulation is optimum and follicular development is adequate there is no need of surrogate $\mathrm{LH}$ for triggering of ovulation in stimulated cycles where specific timing is not necessary like IUI. Half life of hCG is long about 6 days, so chance of hyperstimulation is there if applied in multiple follicles. For administration of hCG cycle should be monitored to detect appropriate time of use. If it can be avoided patient does not need to come to the facility for monitoring in each cycle. Monitoring will be needed only to fix the type and dose of the drug. Once adequate response is achieved by a single or combination drug automatic endogenous LH surge will occur. Subsequently the selected regime can be applied for next few cycles without monitoring. By this protocol ovulation can be achieved and it can save the time and money of the patient and relieves from stress of visit to doctors chamber.

\section{References:}

1. Fowler P/A. The nature and function of putative gonadotropin surge attenuating/ inhibiting factors (GnSAF/IF). Endocrine Rev. 1996;17:10-20

2. Holf JD Quigley ME, Yen SSC. Hormonal dynamics at midcycle: a re -evaluation. J Clin endocrinol metab. 1983;57:792-796.

3. Adams JM, Taylor AE, Schoenfeld DA, Crowkey WF, Hall JE. The mid cycle gonadotropin surge in normal women occurs in the face of an unchanging gonadotropin releasing hormone pulse frequency. J Clin Endocrinol Metab. 1994;79:858-864.

4. Pleuso JJ. The role of amplitude of gonadotropin surge in the rat. Fertil Steril. 1990;53:150-154.

5. Revised 2003 consensus on diagnostic criteria and long-term health risks related to polycystic ovary syndrome. Rotterdam ESHERE/ASRMSponsored Consensus Workshop Group. Fertil Steril 2004; 81(1): 19-25.

6. Knobil E. Discovery of the hypothalamic gonadotropin releasing hormone pulsegenerator and of its physiologic significance. Endocrinology 1992;131:1005-1006.

7. de Koning J, Lambalk CB, Helmerhorst FM, Helder MN. Is GnRH self-priming an obligatory feature of the reproductive cycle? Hum Reprod 2001;16:209-21.

8. Batista MC, Cartledge TP, Zellmer AW, Nieman LK, Loriaux DL, Merrian GR. The antiprogestin RU486delays the midcycle LH surge and ovulation in gonadotropin-releasing hormoneinduced cycles. Fertil Steril 1994;62:28-34.

9. Seibel MM, Kamrava MM, McArdle C, Taymor ML. Treatment of PCO disease with chronic low dose follicle stimulating hormone, biochemical change and ultrasound correlation. Int J Fertil 1984;29:39-43.

10. Glasier A, Hillia SA, Thatcher SS, Barrd DT, Wicking EJ. Superovulation with exogenous gonadotropins does not inhibit the leutinizing hormone surge. Fertil Steril 1988;49:81-85.

11. Killick S, Elstein M Pharmacologic production of luteinized unruptured follicles by prostaglandin synthetase inhibitors. Fertil Steril 1987;47:773-777.

12. Marik J, Hulka J Luteinized unruptured follicle syndrome: a subtle cause of infertility. Fertil Steril 1978;29:270-274.

13. KerinJF, Kirby C, Morris D et al: Incidence of luteinized unruptured follicle phenomenon in cycling women. Fertil Steril 1983;40:620.

14. Mio Y, Toda T, Harada T. Terakawa N: Luteinized unruptured follicle in the early stages of endometriosis as a cause of unexplained infertility. Am J Obstet Gynecol 1992;167: 271

15. Katz E. The luteinized unruptured follicle and other ovulatory dysfunctions. Fertil Steril 1988;50:839.

16. Akil M, Amos RS, Stewart P. Infertility may sometimes be associated with NSAID consumption. Br J Rheumatol 1996;35:76-78.

17. Craft I, Shelton K, Yovich L, Smith D. Ovum retention in the human. Fertil Steril 1980;34:537-541.

18. Beteman BG, Kolp LA, Nunley WC, et al: Oocyte retention after follicle luteinization. Fertil Steril 1990; 199054:793. 